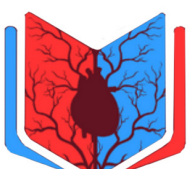

Published By : IVAA

the Indonesian Vascular Access Association

\section{Primary patency of native arteriovenous fistula in elderly at Abdul Wahab Sjahranie Hospital, Samarinda, Indonesia}

CrossMark

\author{
Muhammad Rizki Bachtiar ${ }^{1 *}$, Ivan Joalsen², Izzati Nurmaya Sari', \\ Made Angga Putra ${ }^{1}$
}

\section{ABSTRACT}

Introduction: Arteriovenous fistula (AVF) is preferred to be selected by the patient and clinician due to long term survival and fewer complications than other vascular access. Radiocephalic (RC) fistula is the first choice for dialysis access and should be performed in elderly renal failure patients. Several authors have advocated that the brachiocephalic (BC) fistula should be considered the surgeons' first option. We aim to analyze the primary patency of RC and BC AVF in the elderly.

Method: This prospective cohort study was conducted from June 2018 to March 2020, which included 58 elderly patients who underwent surgery to create AVF. Demographic data were collected from medical records. Meanwhile, information about patient's primary patency of RC and BC AVF were followed up to first access dysfunction or any intervention by phone. The survival data were analyzed using the Kaplan-Meier method

Result: There were 58 elderly patients divided into 51 (87.9\%) patients with RC, 4 (6.9\%) patients with BC, and 3 (5.2\%) patients with Basilic Vein Transposition (BVT). The survival rate of RC was $70.5 \%$ after six months and $29.4 \%$ after 12 months. Meanwhile, $50 \%$ of $B C$ patients survived in the first six months, and $25 \%$ survive for a year. On the other hand, 1 of 3 patients died in the BVT group in the first month after access placement due to hemodialysis complication, and the remaining two BVT patients survived in three months.

Conclusion: $\mathrm{RC}$ has a patency rate of $70.5 \%$ in six months and $29.4 \%$ in a year. Choosing the right type and site of the anastomosis is essential as life expectancy increases in the elderly to preserve the veins for future access site.

Keywords: Arteriovenous Fistula, Elderly, Primary Patency

Cite This Article: Bachtiar, M.R., Joalsen, I., Sari, I.N., Putra, M.A. 2021. Primary patency of native arteriovenous fistula in elderly at Abdul Wahab Sjahranie Hospital, Samarinda, Indonesia. Journal of Indonesia Vascular Access 1(1): 4-7. D0I : 10.51559/jinava.v1i1.10

Received: 2021-04-26

Accepted: 2021-06-04

Published: 2021-06-16

\section{INTRODUCTION}

As the population ages, the incidence of end-stage renal disease (ESRD) is increasing, resulting in more elderly patients being considered renal replacement therapy, which includes peritoneal dialysis (PD), hemodialysis (HD) or kidney transplantation to sustain life. ${ }^{1-3}$ Hemodialysis is the most common renal replacement therapy used in many countries, and the provision of effective vascular access is fundamental for successful hemodialysis. ${ }^{4}$

The current recommendation explains that the arteriovenous fistula (AVF) is preferred to be selected by the patient and clinician. AVF is used due to long term survival, fewer complications, and lower risk of mortality compared to the other vascular access. On the other side, AVF can experience function failure which is caused by thrombosis and maturation failure of the fistula. The changing demographics and the enhancement number of frail elderly patients may influence AVF function. ${ }^{5}$

Preserving the proximal site is recommended by most of the guidelines for future access. Distal location of AVF in upper extremity, radiocephalic (RC) fistula is the first choice for dialysis access and should be performed in the elderly of renal failure patients. On the other hand, several authors have advocated that brachiocephalic (BC) or brachiobasilic (BB) fistula should be considered the surgeons' first option. Advanced age has consistently been associated with autogenous AV access failure, particularly concerning the RC configuration. ${ }^{1,5}$

The patency of AVF is the primary determinant of the effectiveness of the dialysis. ${ }^{6}$ Since most of the data comes from developed countries, and there is a small number of data from developing countries such as Indonesia, especially East Borneo. In this study, we aim to analyze the primary patency of RC and BC AVF for hemodialysis in the elderly at Abdul Wahab Sjahranie Samarinda Hospital. Therefore, this study aims to analyze the primary patency of native arteriovenous fistula in the elderly.

\section{METHOD}

\section{Sample preparation}

This prospective cohort study included all 
patients who underwent surgery to create AVF between June 1, 2018, and March 30, 2020, at Abdul Wahab Sjahranie Hospital. The patients are then being followed up until July 30, 2020. All patients who were included had RC and BC fistula created for their hemodialysis access. Data collected from medical records are demographics, patient management, and clinical variables of the patients. Patients were followed up by phone until first access dysfunction or any intervention occurred.

The inclusion criteria for this study were patients above 60 years old, patients who underwent arteriovenous fistula surgery for the first time in our hospital from June 2018 to March 2020. Also included those patients with artery diameter $>2 \mathrm{~mm}$ and vein diameter $>2 \mathrm{~mm}$, and patients with end-stage renal disease on maintenance hemodialysis. Meanwhile, the exclusion criteria for this study were AVF that failed to mature; patients died before cannulation and patients who refused to become the subject of research.

\section{Surgical technique}

Cardiothoracic vascular surgeons do operations with experience above 5 years where the procedures were performed with local anesthesia. Patients underwent preoperative clinical assessment, with Doppler ultrasound as an adjunct to clinical examination if required. Identification of artery and vein, distending the vein used normal saline before anastomosis. The

Table 1. Patients characteristic

\begin{tabular}{lc}
\multicolumn{1}{c}{ Variables } & $\mathbf{N}=\mathbf{5 8}$ \\
\hline $\begin{array}{l}\text { Age median (min-max) } \\
\text { Gender n (\%) }\end{array}$ & $65(60-75)$ \\
$\quad$ Male & $33(56.9 \%)$ \\
$\quad$ Female & $25(43.1 \%)$ \\
Anastomosis Type n (\%) & \\
$\quad$ Radiocephalic & $51(87.9 \%)$ \\
$\quad$ Brachiocephalic & $4(6.9 \%)$ \\
$\quad$ Basilic Vein Transposition & $3(5.2 \%)$ \\
Underlying Disease n (\%) & \\
$\quad$ Diabetes Mellitus type II & $15(25.8 \%)$ \\
$\quad$ Hipertension & $15(25.8 \%)$ \\
$\quad$ Diabetes Mellitus type II \& Hypertensions & $27(46.5 \%)$ \\
$\quad$ Others & $1(1.9 \%)$ \\
Frequency of Hemodialysis n (\%) & \\
$\quad$ Once a week & $23(39.6 \%)$ \\
$\quad$ Twice a week & $35(60.4 \%)$ \\
\hline
\end{tabular}

end-to-side anastomosis was created with polypropylene 7-0 with continuous suture for all patients.

\section{Definition of variables}

The primary patency of AV Fistula by the European Society of Vascular Surgery (ESVS) is the interval between AVF creation and the first reintervention for fistula dysfunction, thrombosis, or stenosis. After 4-8 weeks post-operation, AVF was evaluated by surgeons for maturation and AVF cannulation. AVF can be cannulated if there were the presence of thrill, the diameter of vein $>5 \mathrm{~mm}$, distance from skin to draining vein $<6 \mathrm{~mm}$ with flow $>600 \mathrm{ml} / \mathrm{min}$ ) and mature after six times was used adequately for $\mathrm{HD}$ cannulation. The elderly in this study belongs patient above 60 years old or below 60 years according to The World Health Organization.

\section{Statistical analysis}

This study used Kaplan-Meier survival curves to ensure the primary patency of AVF in the elderly. The log-rank test analysis was used to determine the differences between curves. The patient was censored in the event of death, changed to a different treatment modality, stopped hemodialysis, or final measurement of patency. The respective endpoints are the date of the first intervention or AVF failure. Significant $p$-value is $\leq 0.05$. All statistical analyses were performed using
SPSS software (version 24.0)

\section{RESULTS}

Between June 2018 and March 31, 2020, a total of 58 patients older than 60 years were referred to the creation of permanent vascular access for hemodialysis. Out of 58 patients, $33(56.9 \%)$ were males and 25 patients $(43.1 \%)$ were females. During this period, 18 patients (31.03\%) died with functioning AVF. RC AVF was made in 51 (87.9\%) patients, BC AVF was made in 4 (6.9\%) patients, and BVT was made in 3 (5.2\%) patients. At the time of the study, 15 patients $(25.8 \%)$ had diabetes mellitus type 2 (DMT2), 15 (25.8\%) patients had a history of hypertension, 27 patients (46.5\%) had a history of DMT2 and hypertension, and one patient had another. Among them, 23 patients have frequent hemodialysis once a week, and 37 patients twice a week. Patients' characteristics can be seen in Table 1.

The survival data were analyzed using the Kaplan-Meier method, showing an RC access survival rate of $70.5 \%$ after six months and $29.4 \%$ after 12 months. Sixteen patients $(31.3 \%)$ die in the RC group with still functioning access. 2 out of 4 patients (50\%) survived in the first six months on BC access, and one patient (25\%) survived for a year (Table 2). Meanwhile, 1 of 3 patients died in the BVT group in the first month after access placement due to hemodialysis complication and left two BVT access survivors in three months. In this study the primary patency did not differ between RC, BC and BVT ( $\mathrm{p}$ value = 0.6) (Figure 1).

\section{DISCUSSION}

Vascular access is essential for hemodialysis patients. It was made by central venous catheter (CVC) and by creating an arteriovenous fistula or interposing the graft between an artery and vein for needle cannulation. AVF is described as the arterialization of a vein connecting between an artery and a vein. Arteriovenous Graft (AVG) is defined as vascular access using a prosthetic graft. ${ }^{3}$

The Kidney Disease Outcomes Quality Initiative (KDOQI) recommendation is that the patients must have permanent hemodialysis access before starting 


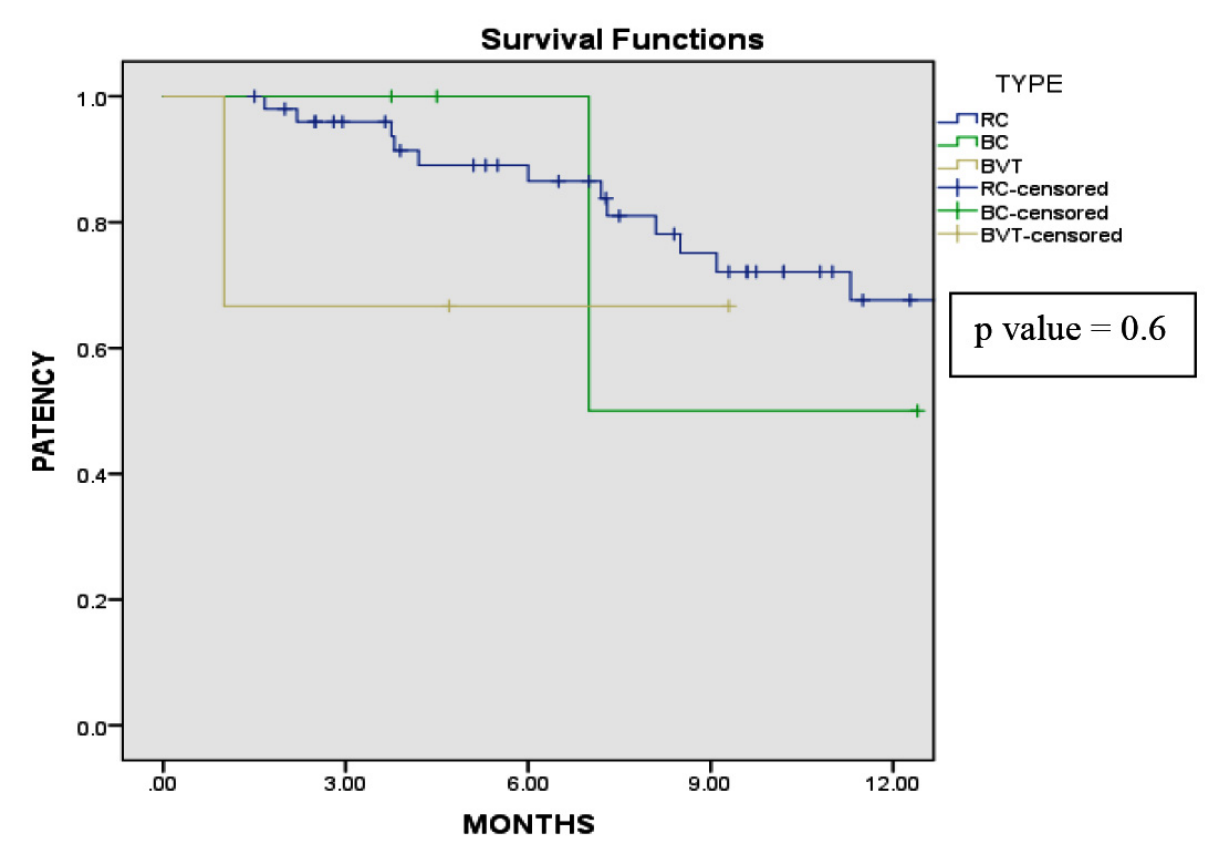

Figure 1. Survival Analysis of Primary Patency AVF

Table 2. Kaplan-Meier Survival Table 12 months of Primary Patency AVF

\begin{tabular}{cccccc}
\hline \multirow{2}{*}{$\begin{array}{c}\text { Types of } \\
\text { AVF }\end{array}$} & \multicolumn{3}{c}{ Survival Rate of Primary Patency } & \multirow{2}{*}{ p value } \\
\cline { 2 - 5 } & $\mathbf{3}$ months & $\mathbf{6}$ months & 9 months & 12 months & \\
\hline RC & $43(84.3 \%)$ & $36(70.5 \%)$ & $26(50.9 \%)$ & $15(29.4 \%)$ & \\
BC & $4(100 \%)$ & $2(50 \%)$ & $1(25 \%)$ & $1(25 \%)$ & 0.6 \\
BVT & $2(67 \%)$ & $0(0 \%)$ & $0(0 \%)$ & $0(0 \%)$ & \\
\hline
\end{tabular}

dialysis. This aim must be supported by early patient referral to perform vascular access by a surgeon for the right site in advance of the target date that the access is suitable for cannulation when needed, by allowing requisite time for maturation. KDOQI panel recommends that patients with glomerular filtration rate lower than $30 \mathrm{ml} / \mathrm{min} / 1.73 \mathrm{~m}^{2}$ (chronic kidney disease stage 4) should be educated about the different renal replacement therapies (transplantation, hemodialysis, peritoneal dialysis). The author recommends that autogenous vascular access can be placed at least six months before the patients start hemodialysis. ${ }^{7}$

Patients should undergo a complete history and physical examination as for any other major vascular surgical procedure, and all medical comorbidities should be optimized. Physical examination should include a thorough pulse examination with Allen's test to determine the dominant blood supply to the hand. Non-invasive imaging in the diagnostic vascular laboratory is the hint of our approach to permanent dialysis access that is used to evaluate vascular conditions. Our criteria for an adequate artery include no hemodynamically significant arterial inflow stenosis and a diameter greater than $2 \mathrm{~mm}$, and those for the vein include no outflow stenosis and peripheral vein segment of suitable length and diameter $>$ $3 \mathrm{~mm}$. These criteria for autogenous access and also likely appropriate for patients being evaluated for prosthetic access. ${ }^{7}$

Several factors have been identified to predict AVF will mature and/or maintain patency. There were several nonmodifiable and modifiable factors. The modifiable factors include smoking, the timing of referral, preoperative ultrasound imaging, anastomotic configuration, anastomotic technique, flow assessment, using antiplatelet agents, and timing cannulation. Non-modifiable factors include diabetes, hypertension, increasing age, pre-dialysis hypotension, artery and vein diameter, arteriosclerosis, and vein distensibility. ${ }^{7}$

Our study presented the long-term primary patency of AVF outcome for hemodialysis patients in a single unit over a 1-year period. It has provided additional data about the representation of primary patency of native arteriovenous fistula in the elderly. KDOQI's guideline recommendation, the first selection for hemodialysis access is an arteriovenous fistula. This is due to RC and BCAVF having superiority in survival, complication, and intervention rates compared with another site or another permanent vascular access. ${ }^{8}$ This study predominantly consists of RC AVF (87.9\%). RC AVF was often selected to preserve future access sites. Thus also to minimize the incidence of related complications such as high-flow access, vascular steal phenomenon, and arterial alteration of cardiac output. ${ }^{9}$

In this study, there were a greater amount of male patients (56.9\%) than females $(43,1 \%)$. The male gender has a larger radial artery diameter than the females. It is an independent predictor for influencing patency due to vascular access caliber difference. ${ }^{10}$ Based on Diehm et al., female gender may affect patency outcome. $^{11}$

Diabetes mellitus affects AVF patency, including reduced arterial calcification and increased vessel diameter and arterial peak systolic volume in nondiabetic patients. ${ }^{10}$ But in this research, we did not compare patency between diabetic and non-diabetic patients. Hypertension induces vascular rigidity and arteriosclerosis that will influence primary patency because it decreases the blood flow to the anastomosis. ${ }^{12}$ From the reference, there were underlying diseases like in our study. From the other study, there had no considerable statistical relationship on several underlying diseases like diabetes mellitus, glomerulonephritis, hypertension, lupus, and uropathy with primary patency of AVF. ${ }^{13}$

Our data shows RC has better patency rates than $\mathrm{BC}$ and BVT in the first six months and 12 months. Borzumati et al. in their study, from January 2000 until August 2008, pointed out that proximal AVF has better patency than distal AVF in the first 12 months (76\% vs $70 \%)^{5}$ A meta-analysis confirms that BC has both superior primary and secondary patency rates at 12 months compared 
with RC. ${ }^{14}$ Misskey J et al. on his study in the twelve months primary patency autogenous arteriovenous access explain that radiocephalic in $<65$ years old was $73 \%, 65-79$ years old was $65 \%$ and $>80$ years old was $65 \%$. The primary patency of brachiocephalic in $<65$ years was $83 \%$, $65-79$ years old was $80 \%$, and $>80$ years old was $79 \%$. From this study, it can be concluded that brachiocephalic have better primary patency than radiocephalic. ${ }^{15}$

If we look from the study based from Asian population there were some study that explain the primary patency of AVF $\mathrm{RC}$ and $\mathrm{BC}$ in elderly. The study at Indian population from Gaur et al. explain that the primary patency of BC AVF has better patency than RC AVF in first 12 months (70.5\% vs $58.3 \%) .{ }^{2}$ Lo et al. in their study with Asian population in Singapore explain that the primary patency of RC after 12 months was $33 \% .^{10}$

However, the brachiocephalic type is at greater risk of peripheral ischemia because occurs increased blood flow to the right heart from fistula and eccentric ventricular hypertrophy due to the volume overload. This would lead one to believe BC type of access may less suitable for elderly patients. ${ }^{16}$ Radiocephalic also provides reasonably good survival rates with acceptable complications in the elderly population. ${ }^{2}$

However, this study has several limitations such as small population, information biases due to its retrospective design, and we did not review patients' body mass index. Our result also may affect by the high mortality of elderly patients, which earlier death happened in patients with still functioning access.

\section{CONCLUSION}

$\mathrm{RC}$ has the most significant proportion in our study, with a patency rate of $70.5 \%$ in six months and $29.4 \%$ in a year. Choosing the right type and site of the anastomosis is important as life expectancy increased in the elderly, to preserve the veins for future access site and prevent the complication of arteriovenous fistula creation.

\section{DISCLOSURES}

\section{Conflict of Interest}

The authors declare that there is no conflict of interest regarding publication of this article.

\section{Funding}

This study doesn't receive any specific grant from government or any private sectors.

\section{Ethical statement}

The Health Research Ethics Committee of RSUD A. Wahab Sjahranie Samarinda has approved this study protocol with registration number 249/KEPK-AWS/ IX/2020.

\section{Author contribution}

Muhammad Rizki Bachtiar contributes define intelectual content, search literature, clinical studies, data analysis, statistical analysis, manuscript preparation, and manuscript editing. Ivan Joalsen contributes define intelectual content, do the surgery procedure, clinical study, data analysis, manuscript editing, manuscript review and as guarantor. Izzati Nurmaya Sari contributes literature search, data analysis, statistical analysis, and manuscript preparation. Made Angga Putra contributes literature search, statistical analysis, and manuscript editing. All authors contribute concept, design, data acquisition, manuscript review.

\section{REFFERENCES}

1. Goh MA, Ali JM, Iype S, Pettigrew GJ. Outcomes of primary arteriovenous fistulas in patients older than 70 years. J Vasc Surg. 2016;63(5):1333-40. Available from: http:// dx.doi.org/10.1016/j.jvs.2015.12.044

2. Gaur P, Srivastava A, Sureka SK, Kapoor R, Ansari MS, Singh UP. Outcomes of Primary Arteriovenous Fistula for Hemodialysis in Elderly Patients ( $>65$ Years) with End Stage Renal Disease: A Study on Indian Population. Indian J Nephrol. 2019;29(6):387-92. Available from: https://pubmed.ncbi.nlm.nih. gov/31798219

3. Wilmink T. Vascular Access: Clinical Practice Guidelines of the European Society for Vascular Surgery. Eur J Vasc Endovasc Surg. 2018;55(6):753-4. Available from: http://dx.doi. org/10.1016/j.ejvs.2018.04.004

4. Ekrikpo UE, Udo AI, Ikpeme EE, Effa EE. Haemodialysis in an emerging centre in a developing country: a two year review and predictors of mortality. BMC Nephrol. 2011;12:50. Available from: https://pubmed. ncbi.nlm.nih.gov/21962220

5. Al-Jaishi AA, Oliver MJ, Thomas SM, Lok CE, Zhang JC, Garg AX, et al. Patency Rates of the Arteriovenous Fistula for Hemodialysis:
A Systematic Review and Meta-analysis. Am J Kidney Dis. 2014;63(3):464-78. Available from: http://dx.doi.org/10.1053/j.ajkd.2013.08.023

6. Lammouchi M, Zouaghi M, Hassen M, Rais L, Krid M, Smaoui W, et al. Determinants of patency of arteriovenous fistula in hemodialysis patients. Saudi J Kidney Dis Transplant. 2018;29(3):615. Available from: http://dx.doi. org/10.4103/1319-2442.235183

7. Dosluoglu HH, Harris LM. Hemodialysis Access [Internet]. Rutherford's Vascular Surgery. Elsevier; 2010. p. 1137-54. Available from: http://dx.doi.org/10.1016/b978-1-41605223-4.00075-5

8. WHO. Indicators for the Minimum Data Set Project on Ageing: A Critical Review in sub-Saharan Africa. Harare MDS Work Indic. 2001;1-27. Available from: www.who.int

9. Santoro D, Benedetto F, Mondello P, Pipitò N, Barillà D, Spinelli F, et al. Vascular access for hemodialysis: current perspectives. Int J Nephrol Renovasc Dis. 2014;7:281-94. Available from: https://pubmed.ncbi.nlm.nih.gov/25045278

10. Lo ZJ, Tay WM, Lee Q, Chua JL, Leong Tan GW, Chandrasekar S, et al. Predictors of Radio-cephalic Arteriovenous Fistulae Patency in an Asian Population. J Vasc Access. 2016;17(5):411-6. Available from: http://dx.doi. org/10.5301/jva.5000591

11. Diehm, Berg van den, Schnyder, Bühler, Willenberg, Widmer, et al. Determinants of haemodialysis access survival. Vasa. 2010;39(2):133-9. Available from: http://dx.doi. org/10.1024/0301-1526/a000018

12. Manne V, Vaddi S, Reddy V, Dayapule S. Factors influencing patency of Brescia-Cimino arteriovenous fistulas in hemodialysis patients. Saudi J Kidney Dis Transplant. 2017;28(2):313. Available from: http://dx.doi.org/10.4103/13192442.202759

13. Kazemzadeh GH, Modaghegh MHS, Ravari H, Daliri M, Hoseini L, Nateghi M. Primary patency rate of native $\mathrm{AV}$ fistula: Long term follow up. Int J Clin Exp Med. 2012;5(2):173-8.

14. McGrogan D, Al Shakarchi J, Khawaja A, Nath J, Hodson J, Maxwell AP, et al. Arteriovenous fistula outcomes in the elderly. $J$ Vasc Surg. 2015;62(6):1652-7. Available from: http:// dx.doi.org/10.1016/j.jvs.2015.07.067

15. Misskey J, Faulds J, Sidhu R, Baxter K, Gagnon J, Hsiang Y. Hemodialysis for Elderly Renal Failure Patients: An Age-Based Comparison of Fistula Location, Patency, Maturation, and Patient Survival. J Vasc Surg. 2016;64(2):541. Available from: http://dx.doi.org/10.1016/j. jvs.2016.05.013

16. Borzumati M, Funaro L, Mancini E, Resentini V, Baroni A. Survival and Complications of Arteriovenous Fistula Dialysis Access in an Elderly Population. J Vasc Access. 2013;14(4):330-4. Available from: http://dx.doi. org/10.5301/jva.5000143

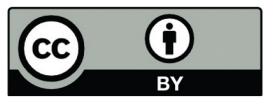

This work is licensed under a Creative Commons Attribution 